\title{
Prescribing safety features of general practice computer systems: evaluation using simulated test cases
}

Bernard Fernando, Boki S P Savelyich, Anthony J Avery, Aziz Sheikh, Mike Bainbridge, Pete Horsfield, Sheila Teasdale

Over $90 \%$ of general practices in the United Kingdom regularly use computers for clinical care. ${ }^{1}$ These computing systems contain drug interaction alerts, and these are considered useful by most general practitioners. ${ }^{2}$ Relatively little attention, however, has been paid to other potential safety features for prescribing, such as contraindication alerts. The NHS Information Authority has regulated use of general practice computer systems through a set of rules known as requirements for accreditation, but these contain only general references to safety and there is evidence that they do not prevent contraindicated prescribing. $^{3}$

Reducing the risks of iatrogenic harm is an important issue for the NHS, and interest has focused on safer prescribing in primary care. ${ }^{4}$ We undertook a laboratory based evaluation of safety features for prescribing of the four main computing systems used in UK primary care. ${ }^{5}$

\section{Method and results}

We used a two round Delphi approach to reach agreement on the most important safety features of general practice computer systems. ${ }^{5}$ This involved electronically circulating a list of 55 theoretically derived statements related to safety to 22 members of a selected multidisciplinary expert panel. Statements related to eight broad themes covering key areas in the medicines management process: prescriber alerts, reports and clinical audit, user interface, repeat prescribing, decision support, coding, monitoring, and links to laboratories.

Over $90 \%$ of the panel judged 32 of these statements to be important, and these were then used to develop 18 scenarios, which were tested using dummy patient records on the four computing systems. The systems (labelled A, B, C, and D in order to preserve suppliers' anonymity) were independently evaluated at Primary Care Information Services (PRIMIS) laboratories by two members of the project team. To minimise risk of bias, systems were tested with each of the scenarios in random order and data were recorded on to piloted data extraction sheets.

We defined the standards against which the computing systems were to be evaluated. These included appropriate alerts when contraindicated drugs or hazardous drug-drug combinations were prescribed. For each scenario, the safety profile of the computing system was categorised as appropriate or inappropriate. Evaluators compared findings, and an agreed mechanism was available for resolving disagreements should these arise. Finally, to ensure

Responses of computer systems tested for prescribing scenarios

\begin{tabular}{|c|c|c|c|c|c|}
\hline \multirow[b]{2}{*}{ Test } & \multirow[b]{2}{*}{ Prescribing scenario tested } & \multicolumn{4}{|c|}{ Alert produced? } \\
\hline & & System A & System B & System C & System D \\
\hline 1 & Aspirin prescribed for child of 8 years & No & No & No & No \\
\hline 2 & Methotrexate prescribed in pregnancy & No & Yes & No & No \\
\hline 3 & Penicillin prescribed in patient with penicillin allergy & No & Yes & Yes & Yes \\
\hline 4 & Oxytetracycline prescribed in a patient with renal impairment & No & Yes & No & No \\
\hline 5 & Enalapril prescribed in patient with renal impairment & No & No & No & No \\
\hline 6 & $\begin{array}{l}\text { Microgynon } 30 \text { (combined contraceptive pill) prescribed in } \\
\text { patient with history of deep vein thrombosis }\end{array}$ & No & No & No & No \\
\hline 7 & $\begin{array}{l}\text { Oxytetracycline prescribed in patient with serum creatinine of } \\
160 \mu \mathrm{mol} / \mathrm{l}\end{array}$ & No & No & No & No \\
\hline 8 & Propranolol prescribed in patient with history of heart failure & No & No & No & No \\
\hline 9 & $\begin{array}{l}\text { Sumatriptan prescribed in patient with history of coronary heart } \\
\text { disease }\end{array}$ & No & No & No & No \\
\hline 10 & $\begin{array}{l}\text { Naproxen prescribed in patient with history of peptic ulcer } \\
\text { disease }\end{array}$ & No & No & No & No \\
\hline 11 & Propranolol prescribed in patient with history of asthma & No & No & No & No \\
\hline$\overline{12}$ & $\begin{array}{l}\text { Sildenafil prescribed to patient already taking isosorbide } \\
\text { mononitrate }\end{array}$ & Yes & Yes & Yes & Yes \\
\hline 13 & Methotrexate prescribed on a daily basis & No & Yes & No & No \\
\hline 14 & $\begin{array}{l}\text { When patient requests salbutamol inhaler it should be clear } \\
\text { whether this has been authorised as a repeat item }\end{array}$ & Yes & Yes & No & No \\
\hline 15 & $\begin{array}{l}\text { Repeat prescription of salbutamol inhaler issued before it is } \\
\text { scheduled }\end{array}$ & Yes & No & No & No \\
\hline 16 & Atenolol prescribed to patient taking amlodipine ${ }^{*}$ & Yes & Yes & $\mathrm{No}^{*}$ & $\mathrm{No}^{*}$ \\
\hline 17 & $\begin{array}{l}\text { Amoxicillin prescribed to patient taking hormone replacement } \\
\text { therapy* }\end{array}$ & $\mathrm{No}^{*}$ & $\mathrm{No}^{*}$ & $\mathrm{No}^{*}$ & Yes \\
\hline 18 & The 10 most frequently used drug pairs with similar names $\dagger$ & No & No & No & No \\
\hline All & No of appropriate alerts & 4 & 7 & 4 & 3 \\
\hline
\end{tabular}

*In these situations "No" was the appropriate outcome since these interactions are clinically irrelevant (but appear as spurious alerts on some systems). t"No" was recorded if systems failed to warn prescribers about all of these drugs with similar names.
Thames Avenue Surgery, Rainham, Kent

Bernard Fernando general practitioner

Division of Primary Care, University of Nottingham, Nottingham NG7 2RD Boki S P Savelyich research associate Anthony J Avery professor of primary health care

Division of Community Health Sciences: GP Section, University of Edinburgh Aziz Sheikh professor of primary care research $\mathcal{E}^{\circ}$ development

PRIMIS, University of Nottingham Mike Bainbridge technical director

Pete Horsfield clinical director Sheila Teasdale service director

Correspondence to: Anthony J Avery tonv.avery@ nottingham.ac.uk

BMJ 2004:328:1171-3 
that there were no technical set-up problems that could have accounted for the observed failures, we reported the problems that were identified to the manufacturers and invited comment.

None of the systems produced alerts for all of the 18 scenarios (table). In terms of prescription of drugs with similar names, none of the systems warned for all 10 drug pairs considered.

The evaluators produced no discrepancies in assessing the safety of systems. Each of the four system suppliers agreed with our assessments.

\section{Comment}

The safety features of computing systems currently in use in about three quarters of UK general practices have clinically important deficiencies. All may fail to warn in a situation when a warning is expected, thus potentially creating a health hazard to patients.

One solution to this problem is to have more explicit regulations about the situations in which suppliers should implement specific alerts. Because information technology, pharmacology, and medicine are dynamic fields, suppliers of systems and drug databases would need to have regular dialogue with end users about ways of further improving the safety features of these important aides to clinical management. Our discussions with manufacturers indicate that many of the problems uncovered could be resolved, and this work is now being taken forward by the National Patient Safety Agency.

We thank the PRIMIS staff for help with the system set up for the evaluation, GP computer system suppliers for responding constructively to our work, and Judy Cantrill and Caroline Morris for their involvement in the Delphi exercise. This work formed a part of BF's MSc thesis which was co-supervised by Dipak Kalra of CHIME, University College, London.

Contributors: AA and BF conceived the study, all authors were involved in study design, $\mathrm{BF}$ and $\mathrm{BS}$ tested the computer systems, all authors were involved in the analysis, and BF, BS, AS, and AA wrote the paper. AA is guarantor.

Funding: National Patient Safety Agency.

Competing interests: Until October $2002 \mathrm{MAB}$ was paid as a medical consultant to Torex Health.

Ethical approval: Not required.

1 Department of Health. Delivering 21st century IT support for the NHS: national strategic programme. London: Department of Health, 2002. www.dh.gov.uk/assetRoot/04/06/71/12/04067112.pdf (accessed 23 www.dh.gov.

2 Magnus D, Rodger S, Avery AJ. GPs' views on computerised drug interaction alerts: questionnaire survey.J Clin Pharm Ther 2002;27:377-82.

Yen-Fu C, Avery AJ, Neil K, Johnson C. Assessing the occurrence and preventability of prescribing potentially hazardous/contraindicated drug combinations in general (family) practice. Pharmacoepidemiol Drug Safety 2001;10:S53.

Wilson T, Sheikh A. Enhancing public safety in primary care. BMJ 2002;324:584-7.

5 Avery AJ, Savelyich B, Teasdale S. Improving the safety features of general practice computer systems. Informatics Prim Care 2003;11:203-6.

(Accepted 25 March 2004)

\title{
Commentary: Computer aided prescribing leaves holes in the safety net
}

\author{
R E Ferner
}

West Midlands Centre for Adverse Drug Reaction Reporting, Cit Hospital, Birmingham B18 7QH

R E Ferner director

r.e.ferner@ bham.ac.uk
Patients die from poor prescribing. As with so much else, poor communication is a major culprit. Amoxil (amoxicillin) is misread as Daonil (glibenclamide) because of bad handwriting; 10U is interpreted as 100 [units] because of inappropriate abbreviation; patients are overdosed with a standard release drug when a modified release formulation was intended but not specified. ${ }^{1}$ The prescribing process is complex, and opportunities for error abound. Patients may be given drugs they are allergic to, or which are contraindicated or have already been prescribed under another name; one drug may interact with another; the dosage, or duration, or formulation, or route may be wrong: in short, anything that can go wrong in prescribing will go wrong.

Computers can help. They reduce medication error rates by as much as $60 \%$ simply by ensuring that prescriptions are legible, complete, and in a standard format. ${ }^{2}$ That is encouraging, but patients still die from the remaining errors. The NHS Information Authority requires that systems used in general practice "shall cross check prescriptions for known sensitivities, interactions and active ingredient duplications in the patient record. An appropriate warning to the prescriber shall be given."
But GP prescribers put their trust in these systems at their patients' peril. Fernando and colleagues tested four computer prescribing systems. ${ }^{4}$ One failed to meet the NHS requirements; others failed to warn of potentially serious prescribing errors, especially where drugs were contraindicated. Contraindications account for about $4 \%$ of adverse drug events in general practice. ${ }^{3}$

The systems could be improved. They might list every contraindication to a drug whenever it was prescribed. That change would trap more errors but risk overwhelming the user with alerts: primary care physicians ignore alerts from nagging computers. ${ }^{5}$ Relevance is the key. Prescribers need not be reminded constantly that etoricoxib is contraindicated in inflammatory bowel disease, that nalidixic acid should be withheld from patients with epilepsy or porphyria, or that hyoscine- $N$-butylbromide should be avoided in patients with myasthenia gravis. Yet timely and relevant warnings will prevent disaster. Hospital systems already exist that link patient history, laboratory results, and prescribing data and that present a hierarchy of warnings to inform, advise, and occasionally forbid the prescriber to continue. ${ }^{6}$ 